\title{
Case Report: Myocarditis along with fulminant hepatic failure secondary to acute hepatitis E infection [version 1; peer
}

\section{review: 2 not approved]}

\author{
Lajpat Rai1', Osama Salam², Uzair Yaqoob (iD2, Ujala Zubair (iD)2
}

1 Jinnah Postgraduate Medical Centre, Karachi, Pakistan

${ }^{2}$ Dow University of Health Sciences, Karachi, Pakistan

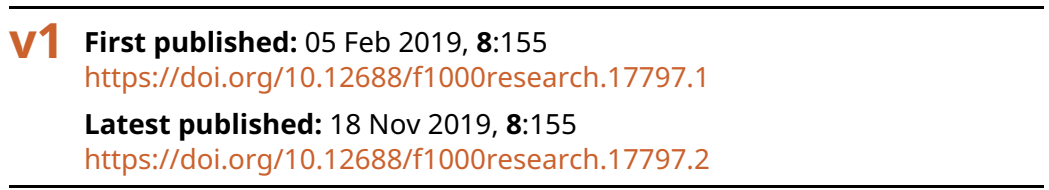

\section{Abstract}

Myocarditis, defined as the inflammation of myocardial tissue has many causes which may be viral, metabolic or bacterial in origin. In this case we report a patient aged 22 years who was admitted with presenting complains of loss of consciousness, generalized muscle rigidity and yellowish discoloration of skin. During the course of his hospital stay, patient developed signs of

myocarditis and later died of hypotensive shock. Viral serology was positive for the presence of hepatitis E virus (HEV), a rare cause of myocarditis. HEV infection can range from asymptomatic disease course to fulminant hepatitis but in rare cases it has been found to be a cause of myocarditis. This is so far the sixth case of hepatitis $E$ induced myocarditis.

\section{Keywords}

Myocarditis, Hepatitis, hepatic failure, Hepatitis E, Acute hepatitis

\section{Open Peer Review \\ Approval Status ? X \\ 1 \\ 2

$\begin{array}{lcc}\text { version 2 } & \text { ? } \\ \text { (revision) } & \text { view } & \text { view } \\ 18 \text { Nov 2019 } & \text { X } & \text { X } \\ \text { version 1 } & \text { view } & \text { view } \\ \text { 05 Feb 2019 } & \end{array}$ \\ 1. Jun Inoue, Tohoku University Graduate School of Medicine, Sendai, Japan \\ 2. Premkumar Madhumita iD, Postgraduate Institute of Medical Education and Research, Chandigarh, India}

Any reports and responses or comments on the article can be found at the end of the article. 
Corresponding author: Uzair Yaqoob (ozair_91393@hotmail.com)

Author roles: Rai L: Conceptualization, Data Curation, Formal Analysis, Funding Acquisition, Investigation, Methodology, Project Administration, Resources, Software, Supervision, Validation, Visualization, Writing - Original Draft Preparation, Writing - Review \& Editing; Salam O: Conceptualization, Data Curation, Formal Analysis, Funding Acquisition, Investigation, Methodology, Project Administration, Resources, Software, Supervision, Validation, Visualization, Writing - Original Draft Preparation, Writing - Review \& Editing; Yaqoob U: Conceptualization, Data Curation, Formal Analysis, Funding Acquisition, Investigation, Methodology, Project Administration, Resources, Software, Supervision, Validation, Visualization, Writing - Original Draft Preparation, Writing - Review \& Editing; Zubair U: Conceptualization, Data Curation, Formal Analysis, Funding Acquisition, Investigation, Methodology, Project Administration, Resources, Software, Supervision, Validation, Visualization, Writing - Original Draft Preparation, Writing - Review \& Editing

Competing interests: No competing interests were disclosed.

Grant information: The author(s) declared that no grants were involved in supporting this work.

Copyright: (c) 2019 Rai L et al. This is an open access article distributed under the terms of the Creative Commons Attribution License, which permits unrestricted use, distribution, and reproduction in any medium, provided the original work is properly cited.

How to cite this article: Rai L, Salam O, Yaqoob U and Zubair U. Case Report: Myocarditis along with fulminant hepatic failure secondary to acute hepatitis E infection [version 1; peer review: 2 not approved] F1000Research 2019, 8:155 https://doi.org/10.12688/f1000research.17797.1

First published: 05 Feb 2019, 8:155 https://doi.org/10.12688/f1000research.17797.1 


\section{Introduction}

Hepatitis E (HEV) virus is an important cause of morbidity and mortality and constitutes a significant public health problem ${ }^{1}$. Hepatitis E transmission includes fecal-oral, vertical and transfusion routes ${ }^{2}$. Symptoms of $\mathrm{HEV}$ infection ranges from asymptomatic to fulminant hepatitis, which is most common in pregnant women. Other extra-hepatic manifestations seen in HEV infection includes Guillian Barre syndrome, neuralgic amyotrophy, glomerulonephritis, cryoglobulinemia, pancreatitis, leukemia, thrombocytopenia, meningitis, thyroiditis, neuro-myopathy, vestibular neuritis and arrhythmias ${ }^{3,4}$. This extra-hepatic involvement seen in an association of HEV is documented in various articles but needs further clinical studies and research ${ }^{3}$. Here we report a rare case of HEV virus associated myocarditis in Karachi, Pakistan. The other four reported cases are documented in India ${ }^{5,6}$. and one case was documented in a western hemisphere traveler ${ }^{7}$.

\section{Case presentation}

A 22 year old male student, from the Sindh province of Pakistan, unmarried, presented to the emergency department of Jinnah Postgraduate Medical Centre, Pakistan, in April 2018 with loss of consciousness, convulsions, and generalized rigidity. He was admitted to the gastroenterology high dependency unit (HDU). On physical examination his temperature was $100^{\circ} \mathrm{F}$, pulse was $136 \mathrm{bpm}$, blood pressure (BP) of $110 / 70 \mathrm{~mm} / \mathrm{Hg}$, and respiratory rate of 28 breaths per minute. The patient was unresponsive to pain with bilateral reactive pupil, and there was a slight yellow skin pigmentation of palms and sole with yellow sclera. The patient was not maintaining oxygen saturation hence intubation and ventilatory support was required and so patient was shifted to the intensive care unit. Abdominal exam was normal without hepatosplenomegaly or ascites, respiratory and heart sounds were audible and normal. His past medical history was negative and was non-contributory. Laboratory parameters at that time revealed, altered liver function tests (LFTs) with serum glutamic pyruvic transaminase (SGPT) $1160 \mathrm{u} / \mathrm{L}$ (reference range, 7-56 u/L); aspartate aminotransferase (AST) $225 \mathrm{u} / \mathrm{L}$ (reference range, 10-40 u/L); gamma-glutamyltransferase (GGT) $51 \mathrm{u} / \mathrm{L}$ (reference range, 9-50 u/L); alkaline phosphatase (ALP) $372 \mathrm{u} / \mathrm{L}$ (reference range, $150-480 \mathrm{u} / \mathrm{L}$ ); serum albumin $4.2 \mathrm{~g} / \mathrm{dL}$ (reference range, 3.5-5.5 $\mathrm{g} / \mathrm{dL}$ ); total bilirubin $4 \mathrm{mg} / \mathrm{dL}$ (reference range, $0.1-1.2 \mathrm{mg} / \mathrm{dL}$ ); platelet time (PT) 13 seconds (reference range, 11-14 seconds); and international normalized ratio (INR) 13 seconds (reference range, 0.9-1.2 seconds). His blood urea was $61 \mathrm{mg} / \mathrm{dl}$ (Reference range, 7-20 mg/dL), serum creatinine of 1.64 (reference range, $0.6-1.2 \mathrm{mg} / \mathrm{dL}$ ), with a normal serum electrolyte panel. A viral screen of the patients blood was ordered and HEV IgM and $\operatorname{IgG}$ was positive, with negative serology for Hepatitis B, Hepatitis C, Hepatitis D, Dengue, Typhoid, Cox-B, Epstein-Barr virus (EBV), Leptospira, Herpes simplex virus, Adenovirus and HIV. Blood cultures were negative, rapid malaria test was negative, labs for antinuclear antibody, anti-mitochondrial antibody and anti-smooth muscle antibody was also negative. Sonographic investigation showed normal abdominal structures. Patient's blood urea and creatinine returned to normal on the second day of admission and LFT's started recovering by the fourth day. On the seventh day of hospitalization, the patient had normal total bilirubin with slightly raised LFT's of ALP $120 \mathrm{u} / \mathrm{l}$, SGPT
$115 \mathrm{u} / \mathrm{l}$, AST $62 \mathrm{u} / \mathrm{l}$, GGT $68 \mathrm{u} / \mathrm{l}$ and platelet of $201 \times 10^{9}$, leukocytes $27 \times 10^{9}$ with high-grade fever. On the seventh day of admission the patient became hypotensive with BP of $92 / 68 \mathrm{~mm} / \mathrm{Hg}$ and a pulse of 148 . Physical examination revealed distended external jugular veins, with bilateral pedal edema and bilateral chest congestion. Chest examination showed decreased respiratory sounds from the right and left lung base with muffled heart sounds. On further investigations and workups a chest $\mathrm{X}$-Ray showed bilateral pulmonary congestion at the base of the lung with cephalization of vessels. An electrocardiography (ECG) showed nonspecific ST segment and T-wave abnormalities with supraventricular tachycardia (Figure 1). Creatinephosphokinase (CPK) came out to be $8414 \mathrm{u} / \mathrm{l}$ (the patient had no history of seizures). Coronary angiography was performed to exclude acute coronary syndrome, which revealed no obstructive lesion in the coronary artery. Echocardiography was performed which demonstrated impaired left ventricular function with diffuse hypokinesia without any pericardial effusion and ejection fraction of $30 \%$. The sign and symptoms together with workups and labs were highly suggestive of myocarditis. The patient was treated accordingly an injection of Risek (40 mg once daily), $25 \%$ dextrose (as per needed), colomycin (2 million IU thrice daily) and moxifloxacin (400 mg once daily), acyclovir (500 $\mathrm{mg}$ thrice daily); syp duphalac (30 ml 6 hourly) was given nasogastrically; and patient was kept sedated with propofol. Despite aggressive medical support, the patient abruptly developed cardiopulmonary arrest on the eighth day of admission, resuscitation was

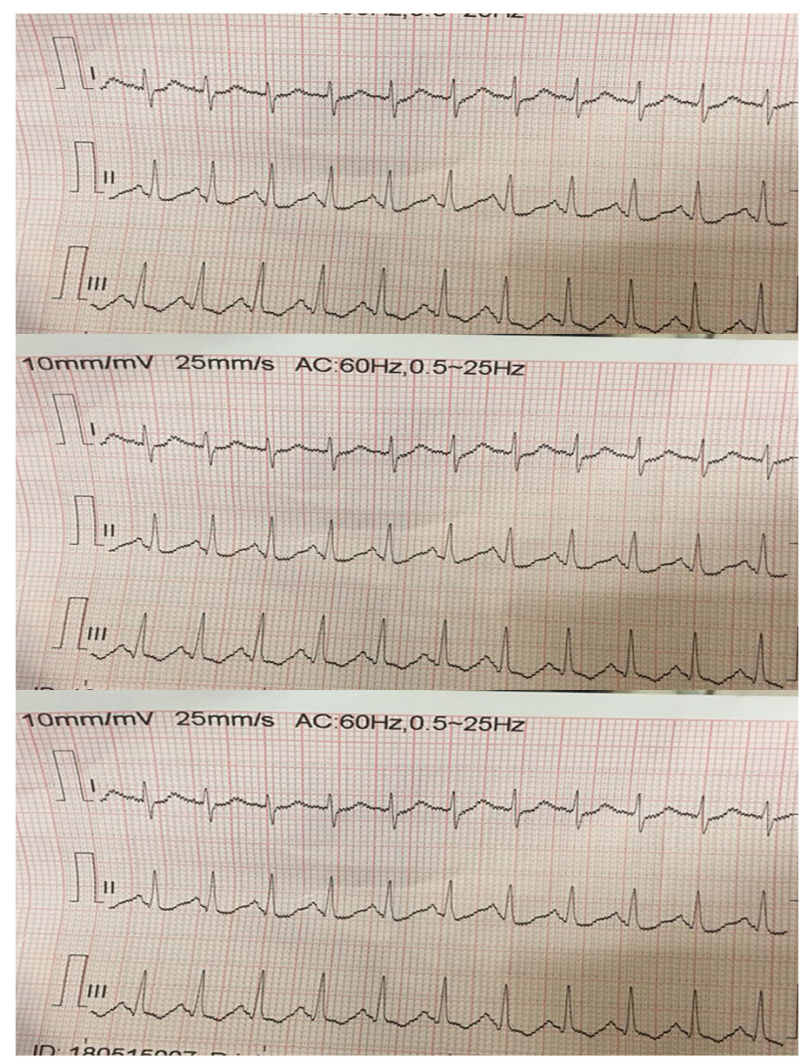

Figure 1. Electrocardiogram of the patient. 
performed but the patient didn't recover and died of cardiopulmonary arrest. More specific investigations were planned but could not be performed post-mortem.

\section{Discussion}

According to the World Health Organization, the annual incidence of HEV infection is 20 million around the globe, with the majority of cases from East and South Asia ${ }^{8}$. It is common in resource-limited countries with limited access to essential water, sanitation and health services. Our patient contracted an acute HEV infection causing acute fulminant hepatitis leading to hepatic encephalopathy, coma and loss of consciousness. He was intubated and managed appropriately in intensive medical care, patients LFT's were recovering but unfortunately, he developed myocarditis and died of cardiopulmonary arrest. Myocarditis is the inflammation of the myocardium with inflammatory infiltrate, necrosis and degeneration of myocytes in the myocardium ${ }^{8}$. Among all other causes of myocarditis, viral etiology appears to be the most common in developed countries, whereas in developing countries its rheumatic carditis, Chagas disease and HIV associated diseases are more common ${ }^{9,10}$. As there is so much clinical variability, diagnosing myocarditis is a challenge. Diagnostic guidelines such as those of American college of cardiology/ American heart association and Dallas criteria provide help with early diagnosis ${ }^{4}$. On eighth hospitalization day, our patient developed hypotension and distended jugular venous distension, pedal edema, bilateral pulmonary edema and muffled heart sounds. On initial workup, cardiac enzymes, ECG, CPK tests were planned. Echocardiography is recommended as an initial diagnostic tool for suspected myocarditis ${ }^{11}$. According to small observational studies, it was suggested that magnetic resonance imaging (MRI) can identify morphological and anatomical changes such as inflammation, edema and myocyte injury in the myocardium. Due to myocardial inflammation $\mathrm{T} 1$ and $\mathrm{T} 2$ relaxation times and spin densities gives accurate tissue characterization ${ }^{12}$. Endomyocardial biopsy is also an important diagnostic tool in myocarditis and sometimes is the only means of diagnosing myocarditis. Endomyocardial biopsy may be used for patients whose condition does not respond to conventional supportive therapy, a patient with acute dilated cardiomyopathy associated with hemodynamic compromise, refractory cases, patients with life-threatening arrhythmias and high-grade AV block $^{13}$. Histological evaluation is also diagnostic for myocarditis, however, because of variable observer interpretations and focal inflammation sampling error can be high ${ }^{14}$. In our case our diagnosis was limited as these confirmatory tests just mentioned i.e. echocardiography, biopsy and MRI, could not be performed due to the early death of the patient.

\section{Consent}

Written informed consent for publication of their clinical details was obtained from the relatives of the patient.

\section{Data availability}

All data underlying the results are available as part of the article and no additional source data are required.

\section{Grant information}

The author(s) declared that no grants were involved in supporting this work.
1. European Association for the Study of the Liver: EASL Clinical Practice Guidelines: management of hepatitis C virus infection. J Hepatol. 2011; 55(2): 245-64.

PubMed Abstract | Publisher Full Text

2. Khati C: Hepatitis E-not so benign after all! J Med Res. 2016; 2(4): 118-20. Reference Source

3. Pischke S, Hartl J, Pas SD, et al.: Hepatitis E virus: Infection beyond the liver? J Hepatol. 2017; 66(5): 1082-95. PubMed Abstract | Publisher Full Text

4. Woolson $\mathrm{KL}$, Forbes $\mathrm{A}$, Vine L, et al.: Extra-hepatic manifestations of autochthonous hepatitis E infection. Aliment Pharmacol Ther. 2014; 40(11-12): 1282-91.

PubMed Abstract | Publisher Full Text

5. Premkumar M, Rangegowda D, Vashishtha $C$, et al.: Acute viral hepatitis e is associated with the development of myocarditis. Case Reports Hepatol. 2015; 2015: 458056

PubMed Abstract | Publisher Full Text | Free Full Text

6. Goyal B, Mishra DK, Kawar R, et al.: Hepatitis E associated myocarditis: an unusual entity. Bombay Hosp J. 2009; 51(3): 361-2. Reference Source

7. Dougherty $\mathrm{T}$, Showkat B, Adam MK, et al.: Acute myopericarditis due to Hepatitis $E$ virus infection: the first reported case in the western hemisphere. J Gastrointest Dig Syst. 2016; 6: 386. Publisher Full Text
8. Maisch B, Portig I, Ristic A, et al.: Definition of inflammatory cardiomyopathy (myocarditis): on the way to consensus. A status report. Herz. 2000; 25(3): 200-9.

PubMed Abstract | Publisher Full Text

9. Cooper LT Jr: Myocarditis. N Engl J Med. 2009; 360(15): 1526-38. PubMed Abstract | Publisher Full Text | Free Full Text

10. Mahrholdt H, Wagner A, Deluigi CC, et al.: Presentation, patterns of myocardial damage, and clinical course of viral myocarditis. Circulation. 2006; 114(15): 1581-90.

PubMed Abstract | Publisher Full Text

11. Pinamonti B, Alberti E, Cigalotto A, et al:: Echocardiographic findings in myocarditis. Am J Cardiol. 1988; 62(4): 285-91. PubMed Abstract | Publisher Full Text

12. Laissy JP, Messin B, Varenne O, et al.: MRI of acute myocarditis: a comprehensive approach based on various imaging sequences. Chest. 2002; 122(5): 1638-48. PubMed Abstract | Publisher Full Text

13. Schultz JC, Hilliard AA, Cooper LT Jr, et al.: Diagnosis and treatment of viral myocarditis. In: Mayo Clin Proc. Elsevier. 2009; 84(11): 1001-1009. PubMed Abstract | Publisher Full Text | Free Full Text

14. Baughman KL: Diagnosis of myocarditis: death of Dallas criteria. Circulation. 2006; 113(4): 593-5.

PubMed Abstract | Publisher Full Text 


\section{Open Peer Review}

\section{Current Peer Review Status: $\mathrm{X} \times$}

\section{Version 1}

Reviewer Report 08 August 2019

https://doi.org/10.5256/f1000research.19457.r51461

(C) 2019 Madhumita P. This is an open access peer review report distributed under the terms of the Creative Commons Attribution License, which permits unrestricted use, distribution, and reproduction in any medium, provided the original work is properly cited.

\section{Premkumar Madhumita}

Postgraduate Institute of Medical Education and Research, Chandigarh, India

The case report describes a 22-year old patient who had acute viral Hepatitis E who presented with altered sensorium possibly hepatic encephalopathy, but there are several unexplained details which alter the diagnostic specificity:

1. Why did the patient have generalized muscle rigidity?

2. Clearly, he was intubated for poor sensorium and it is apparent from the clinical examination that he had no heart failure signs at presentation, with normal heart sounds and chest examination.

3. Why are the authors mentioning SGPT on one hand and AST on the other? Surely it will be wiser to use AST and ALT, as is the norm.

4. The authors write 'platelet time (PT) 13 seconds (reference range, 11-14 seconds); and international normalized ratio (INR) 13 seconds (reference range, 0.9-1.2 seconds)'. There is no test called 'platelet time' I believe that they intend to write 'Prothrombin time'. The INR is a ratio. It could not be 13 seconds with the reference range being 0.9-1.2.

5. The authors write 'platelet of $201 \times 10^{9}$, leukocytes $27 \times 10^{9}$ ' No units are mentioned.

6. The sign and symptoms together with workups and labs were highly suggestive of myocarditis. The criteria for myocarditis need to be met. It is likely the patient was in sepsis. The levels of biomarkers like Troponin I and T is not mentioned. Also, the MB fraction of creatine kinase needs to be done in serial tests. Echocardiographic images would be required. The ECG supplied shows sinus tachycardia with secondary ST-T changes.

7. The patient was treated accordingly an injection of Risek ( $40 \mathrm{mg}$ once daily), $25 \%$ dextrose (as per needed), colomycin ( 2 million IU thrice daily) and moxifloxacin (400 mg once daily), acyclovir (500 mg thrice daily); syp duphalac ( $30 \mathrm{ml} 6$ hourly) was given nasogastrically; and patient was kept sedated with propofol. Please avoid use tradenames of drugs used in the 
treatment. The indication for acyclovir is unclear.

8. When was the coronary angiogram done? Are images available? Was there a suspicion of acute coronary syndrome in this patient?

Is the background of the case's history and progression described in sufficient detail? Partly

Are enough details provided of any physical examination and diagnostic tests, treatment given and outcomes?

No

Is sufficient discussion included of the importance of the findings and their relevance to future understanding of disease processes, diagnosis or treatment?

No

Is the case presented with sufficient detail to be useful for other practitioners? No

Competing Interests: No competing interests were disclosed.

Reviewer Expertise: Cirrhotic cardiomyopathy, critical care in cirrhosis, coagulation in cirrhosis.

I confirm that I have read this submission and believe that I have an appropriate level of expertise to state that I do not consider it to be of an acceptable scientific standard, for reasons outlined above.

Author Response 05 Nov 2019

Uzair Yaqoob, Dow University of Health Sciences, Karachi, Pakistan

(Responses numbered acc to comments)

1.Patient was in hepatic encephalopathy and was showing signs of raised ICP due to which muscle tone was

increased and muscle rigidity was present.

2. Exactly, there were no signs of myocarditis on presentation. After patient was intubated and kept under support,

he became hemodynamically unstable and arrhythmic.

3. done in the next update

4. Corrections made in the next update

5. Mentioned in the next update

6. Agreed, all these investigations were planned but due to the unfortunate demise of the patient, these could not

be done. Portable echocardiogram was since the patient was on mechanical ventilation, where just the important

findings are given by an experienced radiologist on a wriiten note, so due to the limited resources in our setup 
images could not be provided

7. Names corrected, since viral myocarditis was suspected, we started acyclovir

8. It was planned, but as mentioned, could not be done

Competing Interests: No competing interests were disclosed.

Reviewer Report 15 July 2019

https://doi.org/10.5256/f1000research.19457.r50664

(C) 2019 Inoue J. This is an open access peer review report distributed under the terms of the Creative Commons Attribution License, which permits unrestricted use, distribution, and reproduction in any medium, provided the original work is properly cited.

\section{Jun Inoue}

Division of Gastroenterology, Tohoku University Graduate School of Medicine, Sendai, Japan

In this paper, Rai et al. described a patient with acute hepatitis E virus infection who developed acute heart failure. Some cases with hepatitis E virus-associated myocarditis have been reported previously and the authors considered the development of myocarditis also in this case, but the diagnosis was not based on enough tests.

1. The authors diagnosed him as having myocarditis, but the evidence is not enough for the diagnosis.The finding of electrocardiogram is not typical. As discussed in the manuscript, endomyocardial biopsy or other supportive tests are required.

2. In Figure 1, why are the same 3 pictures of electrocardiogram (only lead I, II, and III) shown? 12-lead electrocardiogram should be shown.

3. In Introduction, HEV is an abbreviation of 'hepatitis E virus', not 'hepatitis E'.

4. Please show general names of drugs that were used for this patient.

5. A result of HAV test is not shown.

6. Units of platelet and leukocyte counts are not shown.

7. The characteristics of reported cases with hepatitis E virus-associated myocarditis should be described in the discussion section.

Is the background of the case's history and progression described in sufficient detail? Yes

Are enough details provided of any physical examination and diagnostic tests, treatment given and outcomes? 
Partly

Is sufficient discussion included of the importance of the findings and their relevance to future understanding of disease processes, diagnosis or treatment?

No

Is the case presented with sufficient detail to be useful for other practitioners?

No

Competing Interests: No competing interests were disclosed.

Reviewer Expertise: Hepatology, Viral hepatitis

I confirm that I have read this submission and believe that I have an appropriate level of expertise to state that I do not consider it to be of an acceptable scientific standard, for reasons outlined above.

\section{Author Response 05 Nov 2019}

Uzair Yaqoob, Dow University of Health Sciences, Karachi, Pakistan

Thank you so much for taking your time out and reviewing our work. we have worked and updated our article according to your comments and it will soon be online. Can you please elaborate Number "7" of your comments a little more?

Competing Interests: No competing interests were disclosed.

\section{Author Response 05 Nov 2019}

Uzair Yaqoob, Dow University of Health Sciences, Karachi, Pakistan

(Response to rest of the comments)

1.as patient was on mechanical ventilation, he had dyspnoea, became tachycardic with raised JVP, ECG got done showed ST-T wave abnormalities along with SVT, and

Echocardiogram showed Ejection fraction of $30 \%$. So on

basis of ECG, Echocardiogram and clinical findings patient diagnosed as myocarditis.

2. added in the updated version, with apologies for the mistake earlier

3. Corrected

4.done

5. Added, it was non-reactive

6. Added

Competing Interests: No competing interests were disclosed. 
The benefits of publishing with F1000Research:

- Your article is published within days, with no editorial bias

- You can publish traditional articles, null/negative results, case reports, data notes and more

- The peer review process is transparent and collaborative

- Your article is indexed in PubMed after passing peer review

- Dedicated customer support at every stage

For pre-submission enquiries, contact research@f1000.com 